\title{
Thermal comfort in Lebanese residential unit case studies: a coastal region in Lebanon
}

\author{
O. Omar \& Y. Sabsaby \\ Faculty of Architectural Engineering, Beirut Arab University, Lebanon
}

\begin{abstract}
The continuity of urbanization and the need for housing indirectly create a conflict between providing a better building environment and achieving economic growth. Hence, these conditions may lead to the disregarding of the health and well-being of inhabitants particularly in the least developing countries. Thermal comfort is considered as one of the most important parameters in designing the building to improve the quality of living conditions. This paper searches for the most appropriate strategies in developing comfort in Lebanese coastal housing. It uses the thermal standard for buildings in Lebanon as a reference to measure and assess housing thermal comfort in local Lebanese projects. $67 \%$ of housing in Lebanon consists of apartments in multi floor residential buildings. Accordingly, two different residential units have been chosen as case studies in order to assess the indoor comfort and to examine the perceived problems in thermal comfort in such environments. The result of the in-situ measurement and case study monitoring will indicate the problems faced.

Keywords: thermal comfort, comfort standard, residential building, coastal climate.
\end{abstract}

\section{Introduction}

As a developing country, Lebanon is facing long-term housing problems associated with the increasing demand of the population. Creating a thermally comfortable environment for the appropriate residential type is one of the most important parameters to be considered when designing residential buildings. However, in most cases thermal comfort has not been taken into consideration. High-energy performance buildings are able to save primary energy and reduce 
$\mathrm{CO}_{2}$ emissions. The EU energy policy in the buildings sector, including technical solutions and legal procedures, aims to improve energy performance of building and to guarantee human comfort. Several solutions could be used to reduce energy consumption, the easiest of which would be to reduce the indoor temperature for saving energy for heating on the space. However, this may not be the proper solution because energy saving should guarantee a minimum level of indoor environmental input parameters. The standard (UNI EN 15251 [2]) defines indoor environmental input parameters for design and assessment of energy performance of buildings addressing indoor air quality, thermal environment, lighting and acoustics (Fabbri and Tronchin [3]).

In this paper about buildings in Beirut and Tripoli, two coastal cities of Lebanon will be described. These buildings have been built with the respect to Lebanese Building Law that does not yet contain the thermal standards. The building design lacks the passive house strategies and principles that ensure indoor comfort. The aim of the paper is to know, through examples, the relation between building thermal standards and the indoor conditions in the existing buildings by depending on in situ measurement of the indoor parameter. Comparing other studies about the relationship between human comfort, relative humidity and $\mathrm{CO}_{2}$ emission, in this work a real dwelling building case (and not models) has been evaluated with on-site measuring devices. All the measured parameters refer to the ASHRAE and Lebanese thermal standard and are related to energy performance of building case studies and outside climate data. The thermal comfort of the building was also evaluated through a 24-hour measurement.

\section{Thermal comfort and standards}

The comfort of the occupants of a building is the combination of thermal comfort, visual comfort, acoustic comfort, etc. The (UNI EN ISO 7726 [4]) defines the measurement procedures of all these parameters. The numerical simulation of the environment (or energy) simulation some specific cases allow to evaluate the trend of air temperature, radiant temperature, human body adaption and thermo regulation, in connection with geometrical and thermo physics data input. Some examples of thermal adaption standards and software were reported in (Brager and de Dear [5]). On the other hand, thermal comfort depends on several kinds of parameter:

- $\quad$ Metabolic activity, measured in Met, as in (UNI EN ISO 8996 [6]);

- $\quad$ Clothing, measured in Clo, as in (UNI EN SO 9920 [7]);

- PMV (Predicted Mean Vote) and PPD (Predicted Percentage of Dissatisfied), as in (UNI EN ISO 7730 [8]).

The relations between health and comfort have been studied since the 80s: "The World Health Organization (WHO) concept of health became significant for identifying the concept of a 'healthy building' in terms of building performance (i.e., indoor air quality, thermal comfort, lighting quality and acoustics)". "The health and comfort indicators available today can be looked up from: - The occupants or end-users: such as sick leave, productivity, number of symptoms or 
complaints, health adjusted life indicators, specific building related illnesses" (Bluyssen [9]).

The resultant temperature that affects a person's perception of comfort is a function of numerous varying parameters that interact dynamically throughout the day, week, month, and year. These parameters include: internal heat gains, solar gain, relative humidity, ventilation, infiltration, occupants, thermal transmittance (U-value), area and quality of glazing, internal surface temperature, admittance (thermal mass), external temperature, internal temperature (LGD [10]). There is a difference between summer and winter comfort zones due to seasonal acclimatization relating to climate, clothing, activity and metabolismic changes. For Lebanon, three comfort zones have been defined for each climatic region:

- One for the winter season, from January until March.

- One for the two mid-seasons, from April until June and from October until December.

- $\quad$ One for the summer season, from July until September (LGD [10]).

\subsection{ASHRAE standard}

Thermal environmental comfort is as individual sensation, yet it could be defined by standard. The American Society of Heating Ventilation and Air-conditioning Engineers (ASHRAE) define the thermal comfort in (ASHRAE standard 552004 [11]) - "Thermal Environmental conditions for Human Occupancy". The comfort is defined "as the state of mind that expresses satisfaction with the surrounding environment." Specifically, the indoor parameters that should be controlled and measured are:

- $\quad$ Air temperature (dry bulb temperature);

- Mean radiant temperature;

- Relative humidity;

- Air velocity.

The relationship between the human body and the indoor environment depends on energy and mass exchange, which is necessary in order to maintain homoeothermic balance without human effort. However, people have different metabolism rates and physiological behaviours, and thermal comfort should thus be an acceptable approximation. The PMV model is adopted by the (inter) national standards ISO 7730, (ANSI/ASHRAE standard 55 [11]), and EN 15251 [2] (Olesen [12]). These standards aim to specify the conditions that provide comfort to a majority of healthy building occupants, including older adults (Van Hoof et al. [13]).

\subsection{Lebanese thermal standard}

The Thermal Standard for Buildings in Lebanon 2010 was done to include the new buildings and new parts of buildings that are mainly destined for human occupancy; it is divided into two categories:

- Category 1: Residential buildings;

- Category 2: Non-residential buildings (offices, hotels, schools, etc). 
Moreover, it exempts the buildings and parts of buildings that are not mainly destined for human occupancy such as industrial buildings, storage facilities, warehouses, etc. The Thermal Standard for Buildings (TSB) sets the minimum requirements for the thermal performance of building envelopes. It provides methods for determining compliance with these requirements (ADEME [14]).

- Thermal transmittance "U";

- Solar heat gain coefficient "SHGC".

\section{Case studies: residential unit in a coastal region in Lebanon}

Lebanon is divided into four regions based on temperature, relative humidity and solar radiation. These climatic parameters affect the heating and cooling requirements for local buildings:

Zone 1: A coastal region, having less than 1000 degree-days.

Zone 2: A mid-mountain region, having between 1000, and 2000-degree days.

Zone 3: A high-mountain region, having more than 2000 degree-days.

Zone 4: An inland region, also having between 1000, and 2000-degree days (fig. 1).

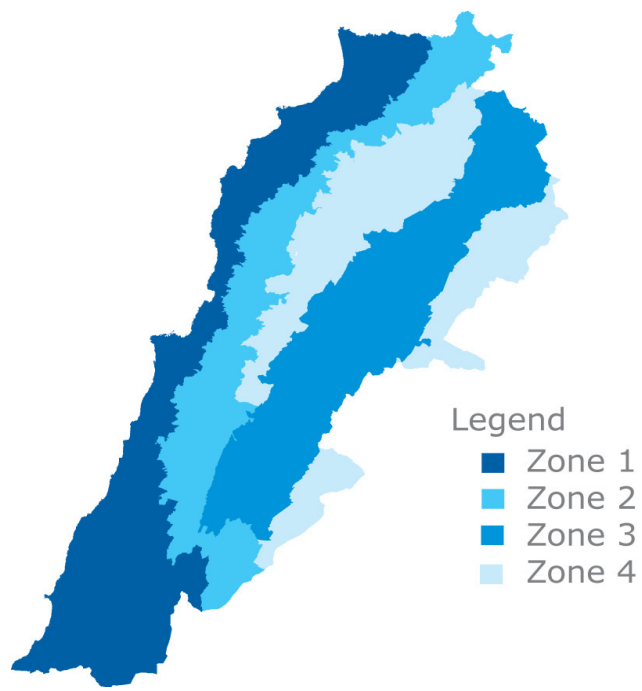

Figure 1: $\quad$ Proposed climatic zones.

\subsection{Background of case studies}

The case studies below are buildings belonging to the coastal zone of Lebanon, the object of which is to study the thermal comfort in a typical residential unit. The first building is Chaarani Building in the city of Tripoli and the second in Beirut. Chaarani Building consists of ten typical units, each on one floor. The unit itself consists of three bedrooms, a kitchen, three bathrooms, and reception and dining rooms. The second case study contains an entrance, one bedroom, one sitting room, and a kitchen (fig. 2). 


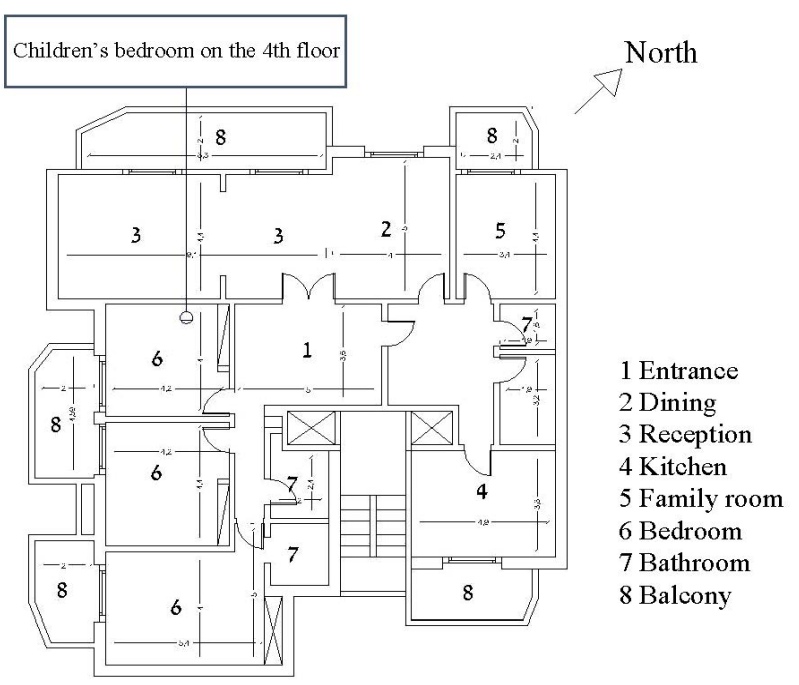

Case study 1

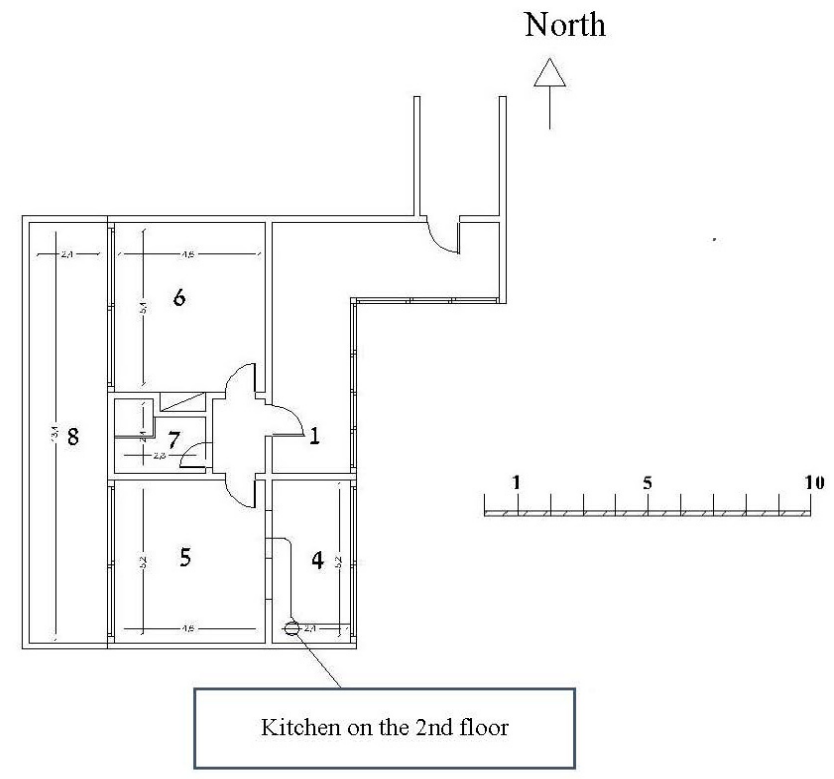

Case study 2

Figure 2: Case study layout.

The covered area of the first case study is $323 \mathrm{~m}^{2}$, while that of the second is $153 \mathrm{~m}^{2}$. The structure used in this project was based on reinforced concrete and masonry block walls as internal wall partitions. The external walls are composed 
of double masonry block walls with $2 \mathrm{~cm}$ air gravity of wall transmittance $\mathrm{U}=$ $1.33 \mathrm{~W} / \mathrm{m}^{2} \mathrm{~K}$. The internal walls are composed of a single layer of hollow block masonry and plaster of wall transmittance $\mathrm{U}=2.5 \mathrm{~W} / \mathrm{m}^{2} \mathrm{~K}$. The typical floor is composed of ceramics, screed, concrete with hourdi blocks and plaster of wall transmittance $\mathrm{U}=1.26 \mathrm{~W} / \mathrm{m}^{2} \mathrm{~K}$. The external openings are single glazing of $\mathrm{U}=$ $6 \mathrm{~W} / \mathrm{m}^{2} \mathrm{~K}$. By comparing, the previous $\mathrm{U}$ values, with the reference value adopted by the Lebanese standard (table 1). We can conclude that the U-values of the external wall and glazing exceed the reference, which necessitates the use of external insulation in external walls and replacing with it (figs 3 and 4).

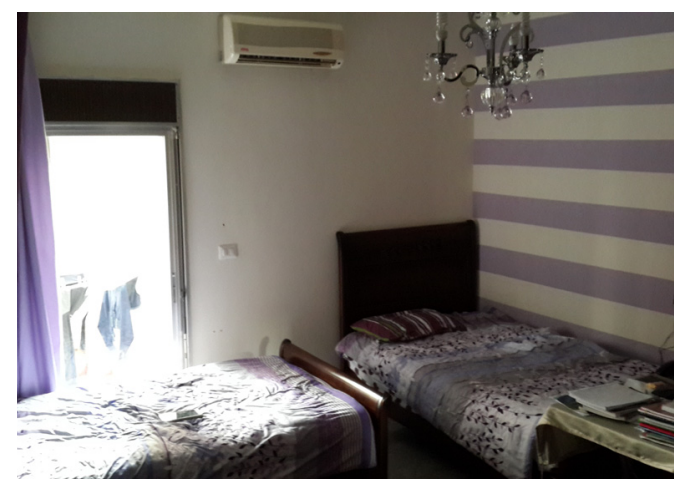

(a)

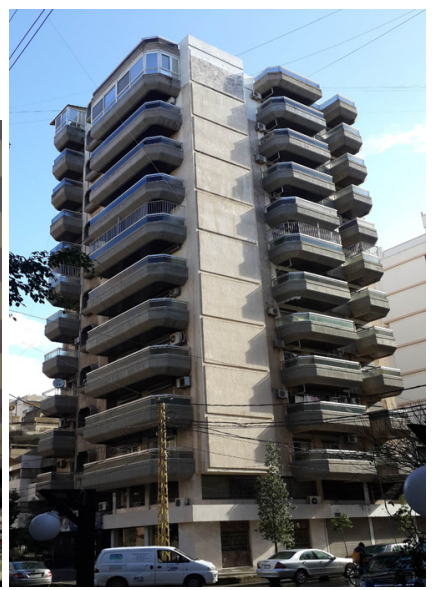

(b)

Figure 3: (a) The children's bedroom of case study 1; (b) Exterior of case study 1 .

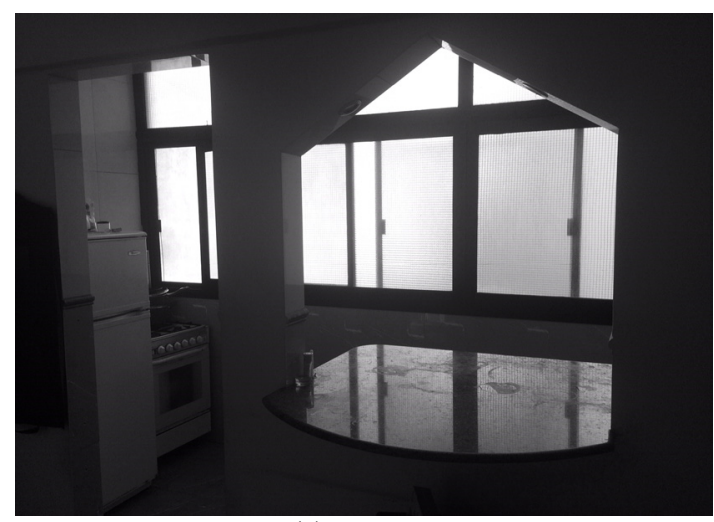

(a)

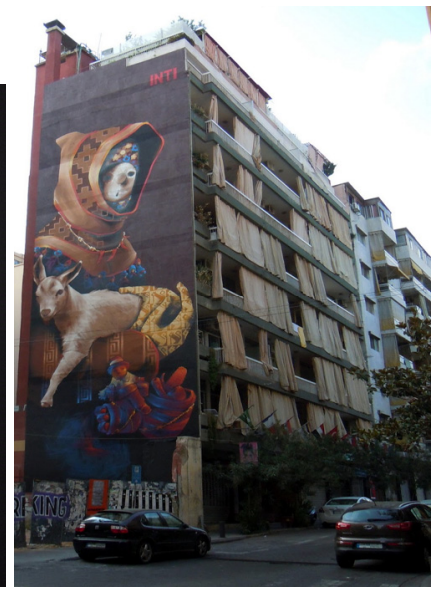

(b)

Figure 4: (a) The kitchen of case study 2; (b) Exterior of case study 2. 
Table 1: Reference thermal transmittance values per component U-ref $\left(\mathrm{W} / \mathrm{m}^{2} \mathrm{~K}\right)$ vs. climatic zone.

\begin{tabular}{|c|c|c|c|c|c|c|}
\hline \multirow{2}{*}{$\begin{array}{c}\text { Climatic } \\
\text { Zone }\end{array}$} & \multirow{2}{*}{$\begin{array}{l}\text { Building } \\
\text { category }\end{array}$} & \multirow{2}{*}{$\begin{array}{l}\text { U-value } \\
\text { Roof }\end{array}$} & \multirow{2}{*}{$\begin{array}{c}\text { U-value } \\
\text { Wall }\end{array}$} & \multirow{2}{*}{$\begin{array}{l}\text { U-value } \\
\text { Window \& } \\
\text { Skylight }\end{array}$} & \multicolumn{2}{|c|}{ U-value Ground Floor } \\
\hline & & & & & Exposed $^{*}$ & $\begin{array}{c}\text { Semi- } \\
\text { exposed }^{\text {tht }}\end{array}$ \\
\hline \multirow[t]{2}{*}{1 Coastal } & 1 Residential & 0.71 & 1.60 & 5.80 & 1.70 & 2.00 \\
\hline & ZNkesidentlal & 0.71 & 1.26 & 5.80 & 1.70 & 2.00 \\
\hline \multirow{2}{*}{$\begin{array}{l}2 \text { Mid } \\
\text { Mountain }\end{array}$} & 1 Residential & 0.63 & 0,77 & 4.00 & 0.77 & 1.20 \\
\hline & 2 N Residential & 0.55 & 0,65 & 3.30 & 0.70 & 1.20 \\
\hline \multirow{2}{*}{$\begin{array}{l}3 \text { Inland } \\
\text { Plateau } \\
\end{array}$} & 1 Residential & 0.63 & 0,77 & 4.00 & 0.77 & 1.20 \\
\hline & 2 N Residential & 0.55 & 0,65 & 3.30 & 0.70 & 1.20 \\
\hline \multirow{2}{*}{$\begin{array}{l}4 \text { High } \\
\text { Mountain }\end{array}$} & 1 Residential & 0.55 & 0.57 & 3.30 & 0.66 & 1.00 \\
\hline & 2 N Residential & 0.55 & 0.57 & 2.60 & 0.66 & 1.00 \\
\hline
\end{tabular}

\subsection{Orientation and thermal zoning}

The first case study has two main elevations (North-West and South-West) due to their location. The occupancy patterns and thermal zoning determined were compared to the building layout (fig. 2). The location of the living area is facing north, which is considered as a cool preferred area. However, the bedrooms are situated to the West, which is considerably hot in the afternoon. The kitchen location to the East is suitable with the prevalent wind direction (fig. 5). In the indoor measurement of temperature, relative humidity and lighting intensity, was located in the children's bedroom of case study 1 ; in case study 2 , the index was measured in addition to the indoor kitchen's emission of $\mathrm{CO}_{2}$ (fig. 4).
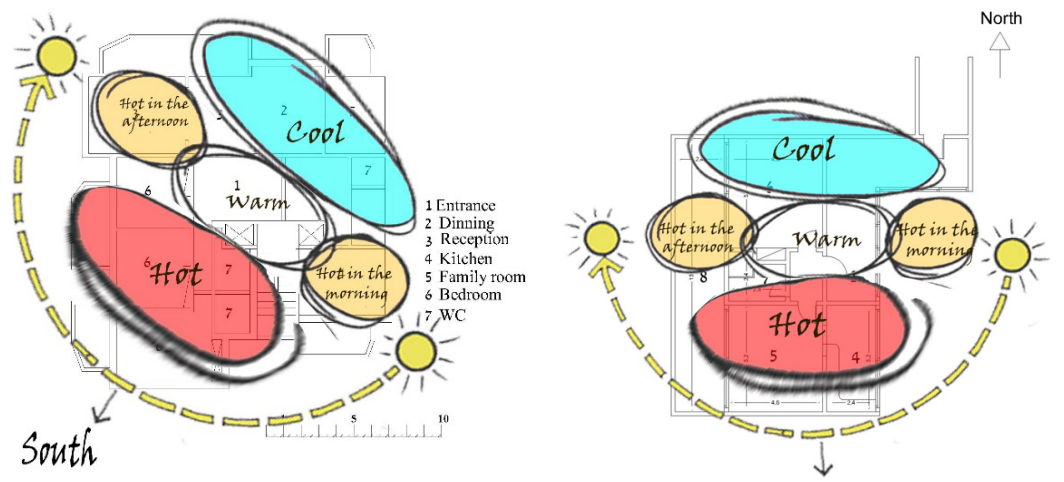

Figure 5: Case study thermal zoning.

\section{Data result thermal and $\mathrm{CO}_{2}$ emission (from measurement equipment)}

The results of the measuring campaign are reported in figures 7 and 8 . The measurement was applied during 48 hours on a typical winter day using a data logger from HOBO Company and a Carbon Dioxide and Temperature Monitor 
from Telaire 7001 (fig. 6); the graphics prove the high value of the relative humidity. In the first case study, the humidity scored $73 \%$ as a maximum at 7:00 am and $55 \%$ as a minimum at $10: 00 \mathrm{pm}$. In the second case study, the highest relative humidity $(85 \%)$ was indicated at 7:00 pm and the lowest $(63 \%)$ at 7:00 $\mathrm{am}$. The indoor temperature in the latter case study scored as high as $23.5^{\circ} \mathrm{C}$ at 8:00 and as low as $19.4^{\circ} \mathrm{C}$ at 5:00 pm. However, in the first case study, the maximum temperature measured was $21^{\circ} \mathrm{C}$ at $7: 00 \mathrm{pm}$ and the minimum was $18^{\circ} \mathrm{C}$ at 8:00 am. The lighting highest intensity measured 450 lux at 2:00 pm and the lowest measured 10-lux. In the first case study, the maximum lighting intensity, measured at 10:00pm, was 230 lux and the minimum was 10 lux during a long period of the day. In the second case study, $\mathrm{CO}_{2}$ emission varied between 500 and $2200 \mathrm{ppm}$. The highest emission was indicate at 6:00pm; while the lowest score, $(500 \mathrm{ppm})$ was indicated at 1:00 am.

Based on previous works and extensive interviews with users, the differences in temperatures and levels of $\mathrm{CO}_{2}$ were a result of the user activity. In this part,
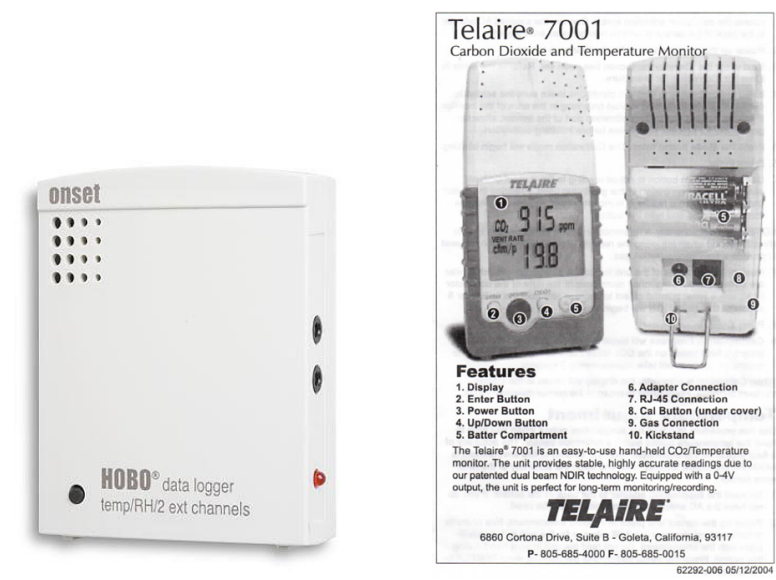

Figure 6: The measurement equipment.

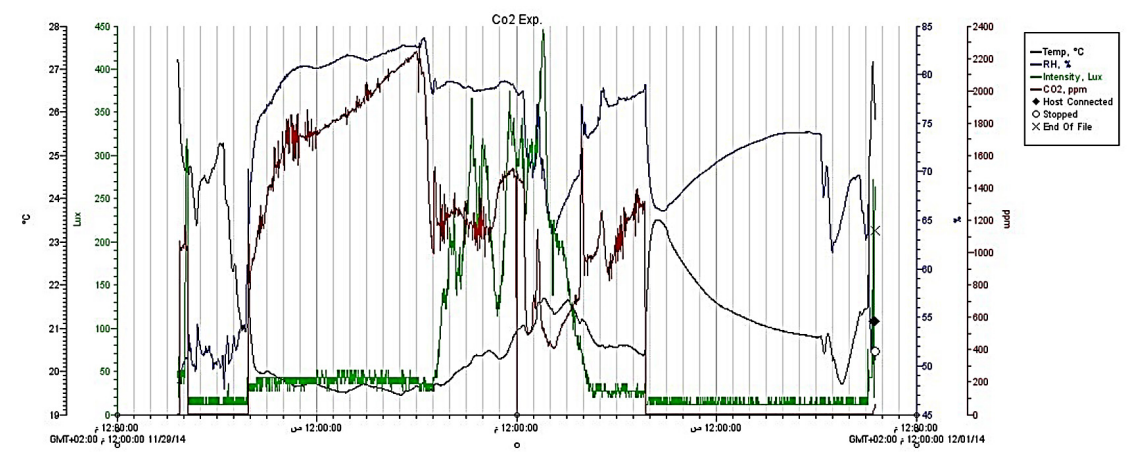

Figure 7: The indoor temperature, relative humidity and intensity of lighting for case study 1. 


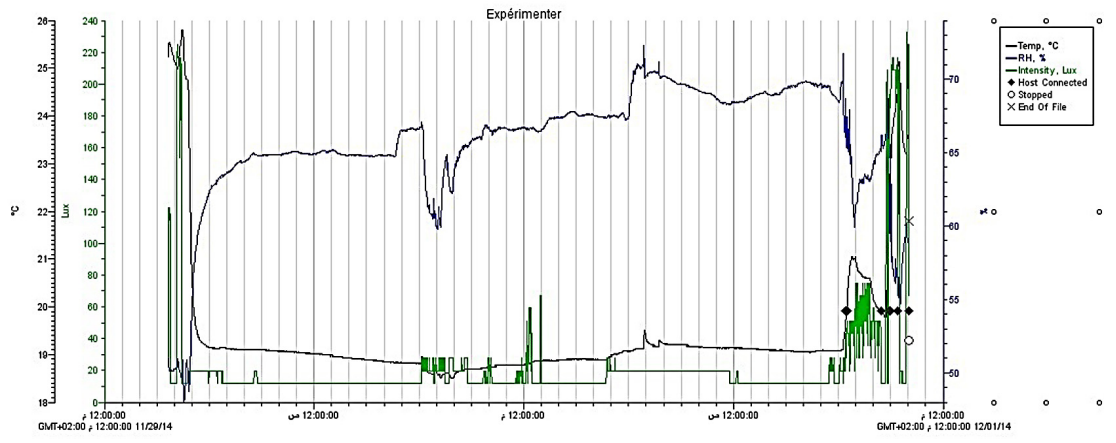

Figure 8: The indoor temperature, relative humidity and intensity of lighting for case study 2 .

we must find the reasons behind the results, focusing on the users' actions and the way their daily lives have influenced these results' appearance. For instance, the rising levels of carbon dioxide in the period between 4 and $6 \mathrm{pm}$ is due to the users' cooking activity while all windows were closed, which led to variation in the $\mathrm{CO}_{2}$ levels in the internal vacuum, especially due to the lack of ventilation systems or central heating. In addition, the rate of moisture in the first and second case studies may be referred to the materials used in the outer insulation of buildings. As for the midnight period when carbon dioxide levels were lowest, we notice that the only source of carbon dioxide was the users' respirational activity.

Finally, the main reasons for the emergence of these results are as follows:

Part I, represented in the wrong activities carried out by users during their daily lives, which leads to high carbon dioxide emission inside the blanks rates, which affects their health and psychological conditions. This can be referred back to the lack of users' awareness of the risks they may face and the procedures they should take.

Part II, represented in the materials used in the building construction, which does not provide a safe or suitable environment for indoor activity for preserving the health and psychological state of the users.

\section{Building thermal environmental engineering solutions}

Many people get sick and miss days of school and work, when their illness could be prevent by keeping up with good quality air, in the home or office. The indoor environmental could have a number of biological airborne pathogens in your air such as bacteria, molds, viruses, dust mites, and hazardous Volatile Organic Compounds originating from furniture, carpets, and paints. For indoor, for examples our homes, we are lacking all of this, not even a sunshine. Therefore, this is why we must take serious action to the matter because the fact is; our buildings cannot do it how mother nature has been doing it all the time (fig. 9).

This paper represents suggestions for improve indoor environmental control of the future, which will contribute to reducing $\mathrm{CO}_{2}$ emissions and humidity, as 


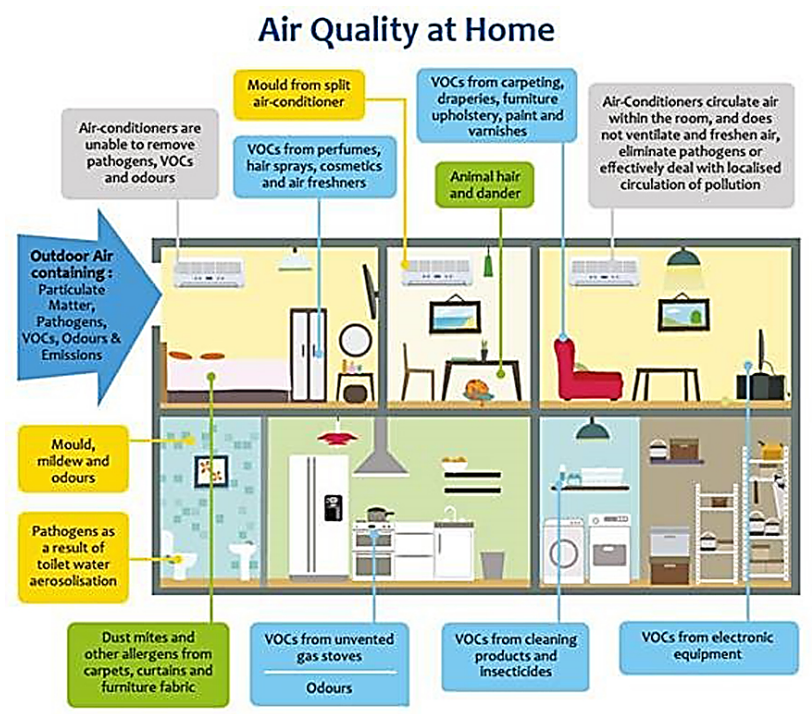

Figure 9: Air quality at home.

well as having almost no heating expenses and an optimum inner climate. Architecturally, the designer for comfort house takes it cue from the bright and simple tradition of Nordic modernism, with a deliberate use of reliable materials such as brick from the exterior. The second case study is closed off towards the north and open, with large glass opening towards the west and east, which is also where the living room and kitchen are located. If replacing the glass materials in the opening to have integrated solid elements to reduce heat loss and screen off the sun. Also, if added Convective loop that can be released as double windows can be implemented by installing double glazing in the west and east elevation on the upper part and lower part of the opening to make renewal ventilation. The suggestion for the first case study is to put dark grey brick with inner walls of wood in balcony; both materials help to create a good insulation for the inner climate which will be perfect to control humidity. The specially developed and manufactured window frames also help to provide heat insulation. Cavity insulation can be thicker than normal; around $300 \mathrm{~mm}$ in the walls and $450 \mathrm{~mm}$ in the floors. The heat can be recycled with the help of heat recovery and controlled ventilation (fig. 10).

This solution can be improving the quality of air inside homes with most economic architectural techniques. During winter days, the louvers at bottom of this window can be opened to allow cold air to pass and become heated by the sunrays, which pass through the balcony space. The louvers at the top of the window will, in turn, be opened to allow the warm air to penetrate into the room and keep it at an adequate temperature. At night, however, the bottom opening will be closed to maintain that warm air inside. During summer days, the louvers at the bottom can be closed while keeping the ones at top opened to allow the discharge of warm air out. Whereas, during summer nights, the louvers 
at the bottom and the top can be opened to allow the passage of cool air in inside through the bottom and the escape of the warm air through the top. In addition, encasing the balcony with glass can be considered as another solution such that the balcony functions as a sun space. It is very important to shed light on the fact that the above solutions are the most economical in the suggestions given to solve the problems that the housing units face in that area with such climatic conditions (figs 10 and 11).

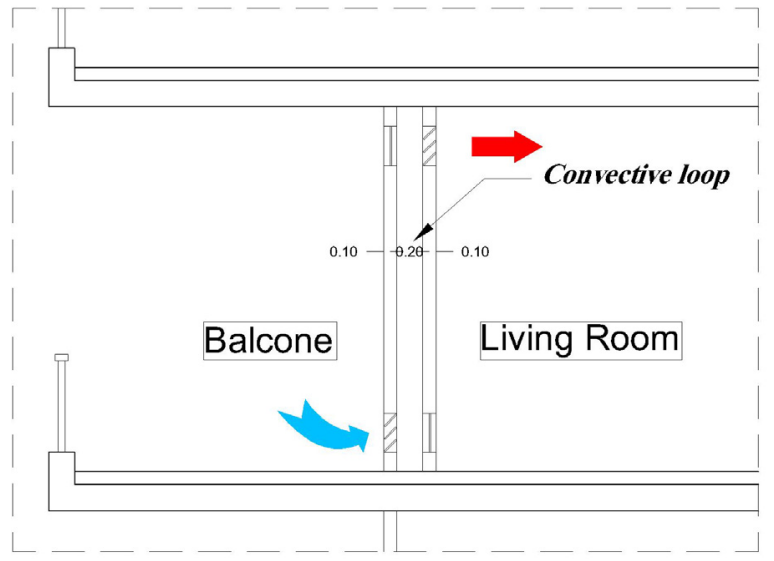

Figure 10: Detail for convective loop (modified by researcher).

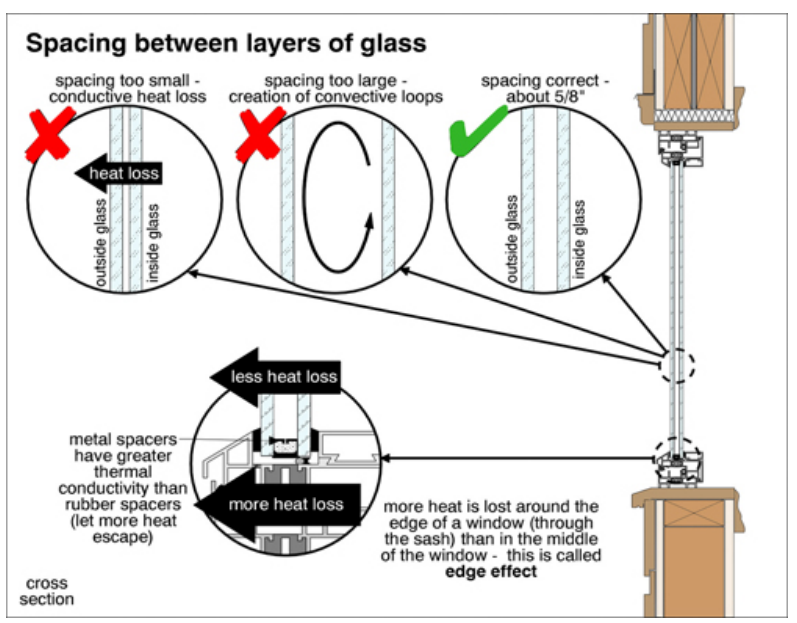

Figure 11: Detail in window glass.

\section{Conclusion}

Clean indoor air quality is always related to fresh air. Clean indoor environment will ensure higher productivity, healthy and safer home. The measurement 
campaign confirms the relationship between thermal comfort conditions and the building envelope performance. A good building insulation with an appropriate orientation guarantees a comfort index of high value. In addition, passive solutions can provide the most architecture technics to improving the quality of Air inside existing homes. In new home design the designer should take into consideration the orientation of buildings, shape of buildings, and the shade system as a min configuration elements in his design or as the main strategy in his design process.

In addition, it is the role of the users in their daily habits and behaviors, which have impressively negative or positive influence on the variation in the levels of carbon dioxide in interior. Negative habits of gas heating or wood burning may have a great effect on the increase of carbon dioxide inside the rooms and living spaces. As can be seen by searching, central ventilation systems are highly needed in most coastal area buildings, as it has a major impact in reducing the high humidity levels. Another solution is through the utilization of insulating materials of high-density works to protect the internal spaces of the effects of humidity, which affect the health of users, especially children and the elderly.

Finally, nanomaterials may play a vital role in minimize the negative effects of air and protecting the interior spaces. Awareness among users ought to be enhanced, especially to the damage resulting from their negative habits inside the blanks.

\section{References}

[1] Tibi Ghaith, Ghaddar Nesreen, Ghali Kamel, Sustainable design guidelines for detached housing in the Lebanese inland region, International Journal of Sustainable Built Environment (2012) 1, 177-193.

[2] UNI EN 15251 (2008) "Indoor environmental input parameters for design and assessment of energy performance of buildings addressing indoor air quality, thermal environment, lighting and acoustics".

[3] Kristian Fabbri, Lamberto Tronchin, thermal comfort and epb in residential building: a commented case study in Ravenna, Italy, Proceedings of Building Simulation 2011: 12th Conference of International Building Performance Simulation Association, Sydney, 1416 November.

[4] UNI EN ISO 7726 (2002) "Ergonomics of the thermal environment Instruments for measuring physical quantities".

[5] Brager G.S., de Dear R. J., "Thermal adaptation in the built environment: a literature review", Energy and Buildings 27 (1998) 83-96.

[6] UNI EN ISO 8996 (2005) "Ergonomics of the thermal environmentDetermination of metabolic rate".

[7] UNI EN ISO 9920 (2009) "Ergonomics of the thermal environmentEstimation of thermal insulation and water vapor resistance of a clothing ensemble". 
[8] UNI EN ISO 7730 (2006) "Moderate thermal environments. Determination of the PMV and PPD indices and specification of the conditions for thermal comfort".

[9] Bluyssen P.M, "Towards new methods and ways to create healthy and comfortable buildings", Building and Environment 45 (2010) 808-818.

[10] Lebanese Governmental Document, Climate and Comfort Passive Design Strategies for Lebanon.

[11] ASHRAE standard 55-2004 "Thermal environmental conditions for human occupancy”. Atlanta, GA, USA: American Society of Heating, Refrigerating and Air-Conditioning Engineers, Inc; 2004.

[12] Olesen B.W, "The philosophy behind EN15251: Indoor environmental criteria for design and calculation of energy performance of buildings", Energy and Buildings 39 (2007) 740-749.

[13] Van Hoof J., Kort H.S.M., Hensen, J.L.M., Duijnstee M.S.H., Rutten P.G.S, "Thermal comfort and the integrated design of homes for older people with dementia" Volume 45, Issue 2, February 2010, pp. 358-370.

[14] ADEME, Thermal Standard for buildings in Lebanon. For New Residential and Non-residential buildings, 2012. 